\title{
Jornalismo: uma relação com opinião pública1
}

\author{
Mayra Rodrigues Gomes² \\ Nara Lya Simões Caetano Cabral ${ }^{3}$
}

\begin{abstract}
Resumo: Este artigo se relaciona a resultados de pesquisa junto a Projeto Temático com apoio da Fapesp desenvolvido a partir do Arquivo Miroel Silveira da ECA-USP. Em nosso eixo de pesquisa, temos investigado as manifestações no jornalismo a respeito da censura a peças e autores teatrais mais proeminentes no cenário cultural brasileiro. Partimos do pressuposto de que quando o jornalismo se manifesta sobre a censura ele o faz em sintonia com a opinião pública. Assim, apresentamos considerações sobre a natureza da opinião pública, os resultados obtidos com nossa pesquisa, até o momento, e compartilhamos nossos achados sobre as condições de conexão entre jornalismo e opinião pública.
\end{abstract}

Palavras-chave: censura, jornalismo, opinião pública.

Abstract: This paper concerns an extensive research on censorship, funded by Fapesp and developed from the Archive Miroel Silveira. In our research line, we investigate journalism manifestations regarding the censorship of stage plays and expressive theatrical authors in the Brazilian cultural dimension. We keep the presupposition that when journalism manifests itself about censorship, he does so in tune with the public opinion. In this article, we present considerations about the nature of public opinion, the results obtained with our research, until this moment, and share our findings about the actual connectivity of journalism to public opinion.

Keywords: censorship, journalism, public opinion. 
Temos empreendido extensa Pesquisa junto ao Projeto Temático Comunicação e Censura - análise teórica e documental de processos censórios a partir do Arquivo Miroel Silveira da Biblioteca da ECA/USP, com apoio da Fapesp e coordenação da Profa. Dra. Maria Cristina Castilho Costa.

A pesquisa tem sido desenvolvida em várias etapas. Na etapa atual, desde 2009, temos investigado as manifestações no jornalismo a respeito da censura a peças e autores teatrais mais proeminentes no cenário cultural brasileiro. As peças teatrais, referência para nossos estudos, pertencem ao Arquivo Miroel Silveira, um acervo com 6.146 processos de censura prévia ao teatro, conduzidos no Estado de São Paulo, entre 1925 e 1970.

Partimos do pressuposto de que, quando o jornalismo se manifesta pró ou contra a censura, ele o faz em sintonia com a opinião pública e que tais manifestações podem ser tomadas, então, como a medida de sua conectividade ao senso comum.

Neste artigo, pretendemos mostrar as modulações de sua conectividade a partir dos levantamentos que fizemos, mas, como consideramos que, até mesmo por seus ideais, o jornalismo visa o tempo todo tal conectividade, também buscamos esclarecer a dimensão em que esses conceitos são tomados por nós.

Por isso buscamos, nessa introdução, definir o caráter da conectividade do jornalismo com a opinião pública para podermos, posteriormente, apresentar com pertinência os casos em que essa conectividade se mostra e que emergem das pesquisas que temos desenvolvido.

Como todos, desde pelo menos dois séculos, pensamos que a tarefa do jornalismo tem como eixo a conectividade com a opinião pública. Este pensamento já se tornou um pressuposto que alimenta muitas de nossas reflexões. Ele se funda na concepção de que o jornalismo, por um lado, sempre dialoga com ela, mesmo que de forma estrita e segmentada, quando direcionado a setores da sociedade ou a interesses específicos. Na realidade, assim posto, mais do que 
dialogar, ele depende de sua conectividade com a opinião pública até mesmo para estabelecer seu nicho de mercado e, afinal, vender seus produtos.

Como todos, por outro lado, pensamos que o jornalismo tem o poder de fazer reverberar, confirmar e promover a confluência de entendimentos que conhecemos com o nome de opinião pública. Concebemos, ainda, que ele pode fazê-lo na forma em que atinge toda a sua dignidade e em que realmente se constitui como serviço público, ao procurar veicular informações com a maior precisão, detalhamento de aspectos e isenção possíveis. Lembramos palavras de Jürgen Habermas que bem expressam essa condição:

A opinião pública se forma na luta dos argumentos em torno de algo, não sem crítica, na aprovação ou rejeição, seja ela ingênua ou plebiscitariamente manipulada, em relação a pessoas, através do common sense. Por isso é que ela precisa ter por objeto antes a apresentação precisa dos fatos do que a pessoa dos governantes (HABERMAS, 1984, p. 85).

A afirmação de Habermas condensa um ideário que, desde o século XIX, nos tem alimentado em relação à natureza das sociedades democráticas, na dependência de ponderação e consenso. Sem informação correta, num mundo em expansão populacional, é inviável o diálogo pressuposto para se atingir decisões equilibradas que visem o bem comum.

Por outro lado, sem um órgão em que se expressem as posições tomadas na esfera pública, em que se organizem as ocorrências em narrativas de forma compreensível e em que se mostre o conjunto geral de opiniões correntes, é impossível a negociação das decisões que respondam adequadamente aos desafios em pauta. Assim, entra em cena o jornalismo como o espaço das informações e, também, como espaço de diálogo e reivindicações.

Universalmente é admitido que a imprensa é o principal meio de contato com o ambiente invisível. E praticamente em todos os lugares se supõe que a imprensa deveria fazer espontaneamente por nós o que a democracia primitiva imaginava que cada um de nós faria espontaneamente para si próprio, e que cada dia e duas vezes ao dia apresentaria a nós uma 
imagem verdadeira do mundo exterior no qual estamos interessados (LIPPMANN, 2008, p. 275).

Esse ideário por todos nós compartilhado, nós que apostamos no jornalismo como meio para alcançar objetivos impregnados de sonhos, entretanto, comporta uma série de pressupostos a serem questionados. $\mathrm{Na}$ realidade, tais pressupostos foram examinados por diversos grandes pensadores, incluindo os autores acima citados, exame que nos orienta no caminho de depuração de conceitos para chegar à natureza da conectividade que o jornalismo mantém com a opinião pública.

Ao longo da história de nossa civilização a idéia de consenso, em torno de uma questão, sobretudo se a questão implicar decisões quanto aos destinos de uma comunidade, tem sido pensada, mesmo onde posições hierárquicas determinam a quem cabe as decisões, como a instância legitimadora das ações a serem assumidas.

As considerações sobre consenso supõem, necessariamente, que ele é precedido pelo senso comum, forma de emergência de opiniões individuais, concebidas pela experiência de vida, pela reflexão e pela tomada de uma posição em meio a uma comunidade. Quando há confluência na assunção de uma ideia por um grupo de pessoas, ideia a ser norteada, evidentemente, pelos interesses de uma comunidade, ocorre a configuração do que se coloca como consenso, manifestando-se, então, num conjunto de posições convergentes a que chamamos de opinião pública.

Contudo, como a questão da opinião em nível individual deve ser considerada em sua relação aos pertencimentos que a determinam, às culturas que as moldam, aos processos educativos que as inoculam, temos um empecilho para o livre e límpido fluxo, resultado de argumentações e ponderações necessários ao estatuto legitimador da opinião pública, entre níveis individuais e níveis coletivos. 
Talvez as palavras de Pierre Bourdieu condensem o problema, já subentendido tanto nas palavras de Habermas quanto nas de Lippmann, da passagem da formação isenta de uma tomada individual de forma que, ao nível público, ela se mostre como efeito de razoabilidade: "(...) O que chamo de 'ethos de classe' (para não dizer 'ética de classe'), isto é, um sistema de valores implícitos que as pessoas interiorizam desde a infância e a partir dos quais produzem respostas a problemas extremamente diferentes" (BOURDIEU, 1983, p. 177).

Diante disso, é a própria ideia de opinião pública que perde, em certa medida, seu estatuto de garantia. No entanto, ainda se reserva a aposta na informação, nas manifestações jornalísticas, como reduto do qual poderia emanar sua confiabilidade.

Nesse caso, devemos perguntar sobre o papel do jornalismo, que supostamente teria a função de fornecer condições de superação das constrições originadas pelas respostas prontas enunciadas por Bourdieu. Tentaremos responder com notações sobre o estatuto das linguagens, afinal, o instrumento que permite a produção jornalística, a saber, a elaboração narrativa dos fatos.

Nomear é trazer à vida, é fazer brotar as coisas do mundo, do mundo como então concebemos, na ordem simbólica. Nesse caso, falamos aqui de uma apresentação, ou melhor, de uma construção do mundo: a terra em que caminhamos, o mar em que nadamos.

Tal apresentação, operação infindável, começa a se processar com as palavras bordejando as coisas, materiais ou imaginárias; continua com os atributos e sentidos colimando-se as palavras; prossegue com a formação de "pontos de basta", aos quais corriqueiramente chamamos de estereótipos. Nesses pontos, todo um entendimento das coisas referidas está embutido, toda cognição pré-configurada e toda orientação, de que precisamos para mergulhar na percepção/absorção de mundo, está dada. 
As palavras, ou nome das coisas, organizam-se em uma língua, como sistema geral que as correlaciona, mas, na realidade e atualidade da comunicação, elas se organizam em enunciados. A um conjunto de enunciados dá-se o nome de discurso, quando eles se agregam porque desenvolvidos em torno de uma temática comum, conteúdo/ideia central, que Ihes confere unidade.

A um conjunto de discursos chamamos de formações discursivas, quando mantêm uma linha comum, tema e ideia, que incide, regulando, sobre campos específicos. Uma formação discursiva traz em seu bojo uma tomada de mundo: uma posição gnosiológica, uma ideologia, uma localização no conjunto dos pensamentos de um tempo e lugar. Caracteriza-se pela demarcação de campos do saber, prático ou teórico, pela demarcação de planos ideológicos, pela demarcação de planos históricos ou epistemológicos.

As formações discursivas se consolidam com a reiteração de temas e campos, num longo período de tempo, que promove e amarra pontos, condensação de dizeres, saberes e ações. Temas e campos, tornados ideias fonte, orientam a dinâmica tanto do protótipo quanto do estereótipo, amarram, fazem ponto e nó, dando tessitura para o conjunto de ideias que circulam na rede cultural.

As formações discursivas, enquanto internalizadas, aparecem como algo brotando espontaneamente de cada indivíduo e têm, portanto, o poder de esconder a extensão de seu poder. Como tal, podemos associá-las a um conjunto de discursos circulantes. Estes, sempre em mutação, conforme as verdades de um tempo e lugar, são aquilo de que se alimentam as conversações, assim como as mídias, uma vez que dão o tom do que nos interessa, o tom do modo de falar sobre esses interesses e a tonalidade de nossas visões de mundo: "O discurso circulante é uma soma empírica de enunciados com visada definicional sobre o que são os seres, as ações, os acontecimentos, suas características, seus comportamentos e os julgamentos a eles ligados" (CHARAUDEAU, 2006, p. 118). 
Assim, em princípio, quando o jornalismo se conecta à opinião pública, sempre remete aos discursos circulantes em determinado tempo e lugar. Este fato é levado em conta neste artigo e nas pesquisas que temos desenvolvido em torno de suas manifestações sobre a censura a peças teatrais.

\section{Uma demonstração}

Em nossa pesquisa, procuramos ver como o jornalismo respondeu a situações em que houve cortes nas peças teatrais, sempre considerando que essa possível resposta é seu modo de conexão com a opinião pública, ou um modo de emergência dos discursos circulantes.

Nossos achados nos levaram a considerar tal conectividade em diversos níveis. Por um lado, há ocasiões em que o jornalismo compartilha um mesmo ideário e age em conformidade com o que é preconizado. Por outro, há situações em que ele contesta discursos circulantes, encampando um projeto maior e inovador, que vem na esteira de mudanças estruturais.

Mas, eles também nos levaram a presenciar o poder do jornalismo, e até de um jornalista específico, como veremos a seguir, de fazer circular discursos, numa direção e na sua contrária, gerando embate de forças, gerando "luta de argumentos". Nesse caso, tais embates estariam um passo além dos discursos circulantes, um passo além em direção à transparente conectividade, ainda que conflituosa, da liberdade de expressão.

Dentre vários autores e peças estudados, destacamos, para trazer aqui, alguns casos relacionados às obras de Max Nunes e de Nelson Rodrigues, porque tais casos são exemplares na demonstração das formas de conectividade a que acabamos de aludir.

O primeiro autor apresenta constante e extensa produção, ao longo de quatro décadas, dedicada à comédia e ao teatro de revista. O segundo era jornalista, bastante ativo e conhecido nesse campo, e desenvolveu produção teatral polêmica que oscila entre a classificação como drama ou como tragédia. 


\section{Max Nunes: o silêncio na imprensa}

Nascido em 1922, Max Nunes fez carreira como humorista e é um dos mais significativos autores de Teatro de Revista do Brasil, com peças encenadas em todo o país. Como testemunho da extensão de sua obra, é substancial sua presença no Arquivo Miroel Silveira: ao todo, há 58 peças cujos documentos dos processos censórios indicam autoria ou co-autoria de Max Nunes. Esses processos datam de 1949 a 1964.

A partir dessas obras, desenvolvemos um rastreamento junto a acervos jornalísticos, a fim de localizar referências na imprensa ao autor em foco e, principalmente, à censura à sua obra. Nessa investigação, consideramos dois veículos de imprensa de grande circulação no Brasil: Folha da Tarde (que, entre 1960 e 1967, foi fundida a outros jornais do mesmo grupo, sendo publicados como Folha de S. Paulo) e O Estado de S. Paulo.

Embora houvesse uma incidência razoavelmente alta de menções às peças de Max Nunes (dado que 54,2\% delas foram citadas), nenhuma referência à censura foi encontrada. Não obstante suas peças fossem muito censuradas devido, sobretudo, às abundantes alusões à sexualidade típicas do Teatro de Revista. Uma parcela significativa - a saber, $21,8 \%$ - dos espetáculos do autor sofreu cortes no texto, sendo $56 \%$ das intervenções (o que perfaz uma grande maioria) de ordem moral (2).

Esse silêncio no jornalismo é muito significativo, sobretudo porque, na época, a imprensa não estava sob censura prévia. No período em foco, tido como democrático, a censura ao jornalismo se tornou menos sistemática e foi exercida de modo mais pontual - sobretudo em comparação ao que ocorria durante a ditadura de Vargas (1930 a 1945). Não obstante, no mesmo período, a censura teatral foi intensificada, como aponta Maria Cristina Castilho Costa: "foi à medida que o teatro se firmava e se desenvolvia como arte e manifestação consciente de expressão dos anseios sociais que a fiscalização endureceu" (COSTA, 2006, p. 141). 
Ocorre que a censura, desde sempre na história da humanidade, representa um mecanismo de regulação da ordem social cuja prática cotidiana se tornou institucionalizada. Por isso, fora de situações extremadas, como regimes autoritários, a censura é concebida, nos discursos circulantes sobre a administração do espaço público, como algo natural.

Como discurso circulante, a censura é desenhada enquanto responsável por zelar pela manutenção da moralidade, ou seja, há a afirmação de uma função moralizante da censura. Ao mesmo tempo, ela acompanha um discurso circulante mais abrangente, a saber, o de princípios morais a serem preservados: o da sexualidade decorosa, o do corpo recatado e o da depuração rigorosa do vocabulário. Essa lógica fica muito evidente no caso de Max Nunes, já que a censura às suas peças é, acima de tudo, moral.

$\mathrm{Na}$ verdade, o teatro de revista era conhecido, justamente, por sua recorrência à sexualidade, pornografia e nudez. Portanto, tendo-se em vista os discursos circulantes sobre a função moralizante da censura e sobre a natureza das revistas teatrais, parece-nos claro, sob a perspectiva desses discursos, que não havia motivos para questionar as determinações censórias à obra de Max Nunes.

Ao silenciar sobre a censura, o jornalismo se mostra conectado à opinião pública, uma vez que essa tem como bandeira o discurso da moralidade. Ao mesmo tempo, com esse silêncio, dá respaldo e reforço a ela e aos discursos que a alimentam. O efeito geral dessa conectividade demonstra um compartilhamento em relação a ambos os discursos: o da moralidade, com seus contornos de então, e o da própria censura, como instrumento de legítima regulação.

\section{Nelson Rodrigues: o jornalismo como mediador de embates}

Nelson Falcão Rodrigues, o dramaturgo brasileiro mais encenado até o momento, nasceu em 1912, no ceio de família numerosa. Seu pai era jornalista bastante conhecido e bastante ativo politicamente, fato que Ihe 
rendeu vários contratempos em meio à ditadura de Getùlio Vargas (19301945). Empreendedor, fundou jornais onde Nelson, assim como dois de seus irmãos, começaram a trabalhar desde cedo.

Com a morte do pai, Nelson Rodrigues passou a escrever para empresas jornalísticas de grande expressão no Brasil, como O Globo, Diários Associados, Última Hora e Correio da Manhã, onde alcançou bastante sucesso com folhetins, com suas crônicas diárias, suas notas sobre futebol.

Paralelamente, a partir de 1940, começou a escrever peças teatrais que foram, de início, vetadas peça censura, para depois se tornarem objeto de negociações que tiveram os jornais como meio influente e, às vezes, decisivo.

Em 1960, passa a trabalhar para a TV Globo, compondo quadro de comentadores de futebol e, em 1967, começa a publicar suas memórias (posteriormente reunidas em livro) no jornal Correio da Manhã.

Tendo apoiado a ditadura militar de 1964, gozava de certo favorecimento, de que fez uso como mediador em defesa de prisioneiros e perseguidos políticos. Tendo enfrentado, ao longo da vida, vários problemas de saúde, morreu em 1980 em virtude das complicações de seu estado.

Posto isso, é necessária a descrição dos temas de suas peças para que se explique o olhar vigilante dedicado pela censura. Embora geralmente classificadas como drama, suas peças constituem um corpo de tragédias em que podem ser vistos os ecos das tragédias gregas. Só que, no caso da obra de Nelson Rodrigues, os temas - incesto, fratricídio, suicídio, aborto etc. - são tomados no contexto da classe média e desenvolvidos com forte ênfase na sexualidade, explicitamente enunciada.

A título de exemplo dessa tônica, citamos a peça Toda nudez será castigada, um grande sucesso, tendo sido encenada muitas vezes e levada ao cinema. Nela, um pai promete a seu filho, no leito de morte da esposa, nunca mais tomar outra mulher. Mas o pai se apaixona por uma prostituta e pensa em 
casar-se com ela. O filho, ao saber disso, cria confusão num bar, razão pela qual é preso. Na prisão é estuprado e, ao sair, decide seduzir a futura madrasta que acaba se apaixonando pelo futuro enteado. O filho, então, foge com o ladrão que o havia estuprado e a madrasta, apaixonada por ele, mata-se, deixando gravação em que conta a história que é, afinal, história da peça.

No Arquivo Miroel Silveira, há treze processos censórios referentes a onze peças de Nelson Rodrigues, muitos dos quais foram bastante extensos, com reviravoltas no interior do aparelho burocrático, sendo frequentemente perpassados por manifestações de setores da sociedade, pró ou contra a censura. São processos datados de 1949 a 1968, que incluem casos de proibição de peças e liberação parcial de espetáculos.

A partir dessas peças, foram levantadas referências à obra do autor junto a acervos jornalísticos, levando-nos a resultados muito diferentes daqueles observados no caso de Max Nunes. Para isso, consideramos uma diversidade de jornais de grande circulação no Brasil: Folha de S. Paulo, O Estado de S. Paulo, Correio da Manhã, A Gazeta, O Globo, Última Hora e Correio Paulistano.

Em tal investigação, foram localizadas, aproximadamente, 46 referências à censura a peças de Nelson Rodrigues que integram o Arquivo Miroel Silveira. A maior parte das menções à censura aparece em textos que abordam as decisões censórias e suas repercussões sem emitir juízo de valor. Não obstante, o fato de se noticiar a censura, por si só, consiste em uma forma de ruptura com o silêncio que predominava na imprensa. Além disso, encontramos também alusões críticas à censura, questionando-a ou relatando os fatos sob o ponto de vista de quem a ela se contrapunha.

Nesse caso, é preciso notar a emergência de um novo discurso em circulação. Trata-se do discurso sobre a liberdade de expressão, como um todo, que vem, progressivamente, orientando o ocidente na luta pelos direitos humanos e pelo direito a informação. 
Emblemático do papel de mediador exercido pelo jornalismo com relação à censura à obra de Nelson Rodrigues é o caso de Perdoa-me por me traíres. O processo censório da peça, extensamente coberto pela imprensa, envolve sucessivas liberações e impugnações, além de manifestações da sociedade civil. Na obra, são abordados temas como prostituição (envolvendo figuras da alta sociedade e adolescentes), adultério feminino, assassinato, incesto e aborto.

Quando, em agosto de 1957, o espetáculo foi proibido pela censura, muitas notas foram veiculadas nos jornais a fim de se noticiar a decisão. Em O Estado de S. Paulo, falava-se das providências necessárias à revisão daquela "arbitrária medida". Simultaneamente, a Comissão Estadual de Teatro manifestou-se contrariamente à interdição de Perdoa-me por me traíres, o que foi reportado pela imprensa. Em uma matéria de $O$ Estado de $S$. Paulo de 5 de setembro de 1957, relata-se que a proibição da peça consistia em medida que merecia "inteira repulsa dos meios teatrais".

No mesmo jornal, foi publicada uma matéria em outubro de 1957, noticiando um encontro entre Nelson Rodrigues e o governador, com a transcrição de longos trechos de falas do autor, defendendo a liberação da peça e elogiando o empenho da imprensa no caso, movida que estava pelo "princípio básico da liberdade de criação artística". A reportagem foi veiculada quando da sugestão, feita pela Comissão Estadual de Teatro, de realização de cortes no texto da peça (sobretudo em relação a uma cena de aborto) e de sua restrição para menores de 21 anos, a fim de evitar a impugnação do espetáculo.

Porém, com a apresentação de uma carta de 110 páginas redigida por uma liga de senhoras católicas em defesa da proibição da peça, a apresentação do espetáculo de Nelson Rodrigues foi novamente vetada.

Quando Herculano Pires, presidente do sindicato de jornalistas e integrante de uma comissão de três membros nomeados pelo chefe do executivo paulista para reavaliar o caso de Perdoa-me por me traíres, votou contra a liberação da peça, o jornal O Estado de S. Paulo publicou um abaixo- 
assinado de profissionais ligados à imprensa. Eles protestavam contra a atitude do presidente do sindicato, "por considerá-la antidemocrática". Ao final, o espetáculo foi definitivamente vetado.

Ainda que a proibição não tenha sido revertida, o jornal noticiou manifestações de associações e entidades de teatro contrárias à decisão censória. Também foi veiculado um extenso texto assinado pelo crítico Décio de Almeida Prado, que condena a interferência de um grupo religioso em assuntos não-religiosos, bem como a censura, por considerá-la contrária a princípios democráticos.

Para compreendermos essa presença da censura teatral nas pautas dos jornais, não se pode desconsiderar que Nelson Rodrigues, sendo conhecido jornalista, buscou fazer com que sua obra fosse comentada e as ações da censura contra ela, noticiadas.

Ao mesmo tempo, ele contava com o apoio de colegas do meio teatral e do jornalismo, conforme Ruy Castro ressalta, diversas vezes, na biografia do dramaturgo. Segundo ele, os censores acreditavam que "a proibição sumária da peça ou simples cortes era tudo que a fome publicitária de Nelson mais queria" (CASTRO, 1992, p. 269).

Não obstante, o que nos interessa prioritariamente aqui é observar que o caso de Nelson Rodrigues representa outro nível de relação entre a imprensa e a censura - ou de conectividade do jornalismo com a opinião pública. O "acordo geral" sobre a prática censória é rompido e a imprensa passa a falar sobre a censura e, até mesmo, a encampar referências críticas a ela.

Em outras palavras, o jornalismo passa a incorporar outros discursos, destoantes dos discursos circulantes consagrados. Como veremos a seguir, ao estimular a publicização das determinações dos censores e o questionamento dessas decisões, Nelson Rodrigues colocava discursos em circulação, os quais contestavam, justamente, uma concepção de censura então enraizada na tradição brasileira. 


\section{Modos de conectividade}

Tendo em vista as raízes coloniais da censura no Brasil, Costa (2006) aponta que o país desenvolveu, no interior de suas instituições, uma profunda necessidade de negociação com os trâmites do poder. Como resultado, desenvolveu-se certa cumplicidade da sociedade em relação aos mecanismos de coerção. Essa ideia, acerca de uma forma de cumplicidade da sociedade com relação à censura, está ligada à existência de formações discursivas sobre a prática censória, que a vêm como mecanismo natural e cotidiano.

A aquiescência a esses discursos circulantes, em que jornalismo e opinião pública estão igualmente imersos, marca um modo de conectividade do jornalismo à opinião pública que pudemos constatar em nosso trajeto. Isso se mostra tanto em relação ao discurso da moralidade quanto em relação ao discurso da própria censura, concebida enquanto provida de uma atribuição moralizante. Nesse caso, ambos os vetores circulantes aparecem como ambiente natural, na normalidade com que o silêncio os marca.

Por outro lado, existe um modo de conectividade que consiste em colocar discursos em circulação, inserindo-os no espaço em que a opinião pública emerge, em outras palavras, em meio a discursos já consolidados. Deste ponto de vista, não importa que Nelson Rodrigues tenha feito publicidade de suas peças a partir dos processos censórios a que elas foram submetidas. Importa e deve se ressaltado que, com esse procedimento, seus artigos jornalísticos colocaram em circulação e sob holofotes pontos possíveis de adesão/conexão. O resultado imediato foi a ruptura com uma abordagem consagrada: a censura não mais foi tratada como um processo natural e incontestável. A partir de então, a censura tornou-se um objeto para ser examinado por todos, tendo a imprensa como mediadora, em relação a sua circunstância e motivação.

É igualmente irrelevante, sob a perspectiva que seguimos, o fato de que, no final, Perdoa-me por me traíres foi proibida no Estado de São Paulo, fato que parece uma derrota dos discursos pela sua liberação. É crucial apontar 
que a própria proibição permitiu a emergência desses novos discursos sobre a censura, sobre a livre expressão e sobre seus limites. Este último, desde então, jamais cessou de circular.

Finalmente, não discutiremos se Perdoa-me por me traíres é realmente crua, chocante, se ela exagera seu foco na sexualidade desviante e na constância do desvio, ou se ela é somente a revelação que, recuperando o título da famosa coluna de Nelson Rodrigues como jornalista, mostrou "a vida como ela é". Mas, devemos ressaltar o fato de que as matérias sobre a peça enfocaram temas antes guardados como tabus de objeto, caso das falas sobre aborto.

Sua prática ilegal era bem conhecida, mas mantida em segredo. Isso significa que, se e quando trazido à conversação, o assunto deveria ser tratado com a desaprovação que faz cessar toda troca de opinião e reduz seu potencial polêmico. O ato de mostrá-la como uma prática comum é obsceno principalmente porque está fora da cena dos discursos circulantes. Pois bem, a sociedade e o jornalismo se conectaram, instalando um discurso circulante sobre o aborto e, ao mesmo tempo, forçando sua abordagem. Como provocação da informação, foram levantadas questões até hoje em aberto em nossa sociedade.

Ao fim da jornada deste artigo, no qual apontamos modos de conectividade entre jornalismo e opinião pública, sendo eles materializados no compartilhamento de discursos circulante ou na inserção de novos, estes não sem fortes polêmicas, retornamos à questão da informação precisa e seu papel na formação de opinião, enquanto livre de circunscrições. Isto porque nesta jornada vimos o papel do jornalismo no embate de argumentos provocados pela informação sobre censura, desta forma construindo linhas de fuga, a partir do centro de um discurso circulante, linhas que foram capazes de colocar outros em circulação.

Neste cenário, o jornalismo mobiliza a opinião pública, fazendo-a pensar a si mesma, justo no ponto de seus vínculos e comprometimentos. Incidindo sobre estes, o jornalismo opera de forma a amarrar-se na conectividade 
suposta no diálogo e assim pode constituir um insuspeitado modo de dispersão das formas consolidadas.

Resta-nos assinalar que o caso acima examinado também remete ao discurso circulante que impulsiona o próprio jornalismo em seu ideal de servir a sustentação de princípios democráticos. No entanto, como pudemos ver, a realização desse ideal está vinculada à conectividade com a opinião pública corrente, de cuja conectividade depende o poder de fazer irradiar outros discursos e, portanto, de fazer circular as bases para outra configuração, igualmente corrente, a sobrepor-se. 


\section{Referências}

BOURDIEU, Pierre. Questões de Sociologia. Rio de Janeiro: Marco Zero, 1983.

CASTRO, Ruy. O anjo pornográfico: a vida de Nelson Rodrigues. São Paulo: Companhia das Letras, 1992.

CHARAUDEAU, Patrick. Discurso das mídias. São Paulo: Contexto, 2006.

COSTA, Maria Cristina Castilho. Censura em cena: teatro e censura no Brasil. São Paulo: Edusp, Fapesp, Imprensa Oficial do Estado de São Paulo, 2006.

HABERMAS, Jürgen. Mudança estrutural da esfera pública: investigações quanto a uma categoria da sociedade burguesa. Rio de Janeiro: Tempo Brasileiro, 1984.

LIPPMANN, Walter. Opinião Pública. Petrópolis: Vozes, 2008.

1 Este artigo é originado do trabalho intitulado "Journalism: the connectivity to public opinion", apresentado pelas autoras na seção Journalism Research and Education da edição de 2011 do Congresso promovido pela International Association for Media and Communication Research (IAMCR), realizado na cidade de Istambul, Turquia. Em nossos estudos a partir do Arquivo Miroel Silveira, as intervenções dos censores foram classificadas em censura moral, política, religiosa ou social.

2 Professora Titular do Departamento de Jornalismo e Editoração da Escola de Comunicações e Artes e do Programa de Pós-Graduação em Ciências da Comunicação da USP. É bolsista de Produtividade em Pesquisa do CNPq e uma das pesquisadoras principais do Projeto Temático Comunicação e Censura análise teórica e documental de processos censórios a partir do Arquivo Miroel Silveira da Biblioteca da ECA-USP. Email: mayrarg@uol.com.br.

3 Graduanda no $8^{\circ}$ semestre do curso de Jornalismo da ECA-USP. É bolsista de iniciação científica da Fapesp sob orientação da Prof. a Dr. a Mayra Rodrigues Gomes junto ao Projeto Temático Comunicação e Censura - análise teórica e documental de processos censórios a partir do Arquivo Miroel Silveira da Biblioteca da ECA-USP, atuando no eixo de pesquisa Liberdade de Expressão: Manifestações no Jornalismo. Email: nara.cabral@usp.br 